\title{
(IMPLICIT) CONSENT TO INTIMACY
}

\author{
Roy G. SPeCe, JR.* \\ JOHN K. HILTON ${ }^{* *}$ \\ JEFFREY N. YOUNGGREN ${ }^{* * *}$
}

\begin{abstract}
We discuss capacity of long-term care residents to consent to intimacy with their spouses/partners and policies to protect residents' rights. The policies provide: (1) competence is presumed; (2) consent can be through explicit verbal or written directives, or, in certain circumstances, by failure to object either verbally or physically; (3) if there is no directive and the facility doubts a resident's competency, it shall require a competency evaluation using a specified approach; (4) residents retain the right to revoke consent regardless of competency, and a prior directive that intimacy ceases if the resident becomes incompetent shall control; (5) residents should be encouraged to include specific instructions should they become incompetent and to appoint a surrogate decisionmaker; (7) unless it becomes obvious that the resident might lack the capacity to object orally or physically or the resident communicates a desire to revoke consent, the facility shall ensure the resident's privacy; (8) if it appears that the resident might lack capacity and is suffering harm, a surrogate or qualified employee can request the spouse/partner to confirm the resident has not verbally or physically refused intimacy; (9) if there is confirmation, a surrogate or qualified employee should bring the matter to court only if she determines that it is in the resident's best interests to cease intimacy, best interests being determined by considering the resident's past representations, other indications of her critical and experiential interests, and her physical and emotional wellbeing; and (10) the court should determine best interests using the same criteria.
\end{abstract}

Persons in nursing homes, assisted living facilities, and care homes (hereafter "nursing homes") face various orthopedic, medical, and psychological challenges common in an aging population. ${ }^{1}$ Frequently, the psychological challenges directly impact cognitive function often leading to a diagnosis of dementia. ${ }^{2}$ Persons with dementia face numerous struggles as the disease progressively attacks their minds and often their bodies. ${ }^{3}$ Early stage dementia, evidenced by

* John D. Lyons Professor, James E. Rogers University of Arizona College of Law.

** 2017 Class, James E. Rogers University of Arizona College of Law.

*** Ph.D., ABPP, Clinical and Forensic Psychology Clinical Professor, University of Missouri.

1. This Article will use the term "nursing home" to refer to all forms of long-term care unless the context calls for a more specific description.

2. Evelyn M. Tenenbaum, To Be or To Exist: Standards for Deciding Whether Dementia Patients in Nursing Homes Should Engage in Intimacy, Sex, and Adultery, 42 IND. L. REV. 675, 706 (2009).

3. Vaughn E. James, No Help for the Helpless: How the Law Has Failed to Serve and Protect Persons Suffering from Alzheimer's Disease, 7 J. HeALth \& Biomed. L. 407, 412-13, 409

http://doi.org/10.18060/4806.1156 
symptoms that may include short-term or transient memory loss, ${ }^{4}$ is embarrassing and may alarm the person and her family about further deterioration. At later stages of dementia, ${ }^{5}$ persons may struggle to remember how to perform activities of daily living, ${ }^{6}$ and, consequently, they often find themselves in a nursing home or residential care facility depending on their degree of impairment. Of course, not all residents ${ }^{7}$ of nursing homes have or develop dementia; often persons are institutionalized because neither they nor a willing friend or relative is able to care for them outside a facility.

Regardless of the reasons for their admission, residents of nursing homes are often subjected to a reduction in the privacy they have enjoyed for decades. They are often forced to comply with an institutional schedule different from that to

(2012).

4. Id. at 411-12.

5. At least seventy-five conditions comprise the "dementia group" of diseases, including vascular dementia, Binswanger's disease, dementia with Lewy bodies, Pick's disease, and Alzheimer's disease. Id. at 409. Of these, Alzheimer's disease is the most prevalent, accounting for more than two-thirds of all dementia cases. Id. Regardless of the specific underlying condition, dementia usually progresses through stages of deficit as outlined here concerning Alzheimer's disease. See Alzheimer's Ass'N, 2015 Alzheimer's Disease Facts And Figures 13-14 (2015), https://www.alz.org/facts/downloads/facts_figures_2015.pdf [https://perma.cc/F5XL-YTLK]. Given that Alzheimer's is the predominant form of dementia, this Article will use the terms interchangeably. See id. at 5 . There is no one authority on defining stages of dementia. Various staging schemas have been developed, such as the National Institute on Aging's and American Alzheimer's Association's three-stage approach, which focuses on Alzheimer's: (1) Preclinical Alzheimer's Disease, in which there are no measurable symptoms but blood biomarkers and physical changes in the brain are present, (2) Mild Cognitive Impairment ("MCI"), in which the person develops mild but measurable changes in thinking abilities, and (3) Dementia Due to Alzheimer's Disease, characterized by noticeable changes in memory, thinking, and behavior that impair a person's ability to function in daily life. Id. at 13-14. More complex staging schemes, such as the Global Deterioration Scale, a seven-stage system based on the severity of a person's cognitive and self-care deficits and psychiatric and behavioral symptoms may also be used in various contexts. Jalayne J. Arias, A Time to Step In: Legal Mechanisms for Protecting Those with Declining Capacity, 39 AM. J.L. \& MED. 134, 192 (2013). Here, what is commonly referred to as "early stage dementia" is equivalent to Mild Cognitive Impairment, and "later stages dementia" may be compared to Dementia Due to Alzheimer's Disease.

6. James, supra note 3, at 413-14.

7. Two-thirds of people diagnosed with Alzheimer's disease are women, and seventy percent of nursing home residents are women. CTR. FOR DiseAse CONTROL, U.S. DEP'T HEALTH \& Hum. SERvs., LONG-TERm CARE Providers ANd SERVICES USERS IN THE United STATES: DATA from the National Study of Long-Term Care Providers 2013-2014, at 37 (2016), https://www.cdc.gov/nchs/data/series/sr_03/sr03_038.pdf [https://perma.cc/FZ4T-LUG4]; 2015 ALZHEIMER's DiSEASE FACTS AND FiguRES, supra note 5, at 17. This Article will use the feminine article when referring to residents. This is not intended to diminish the plight of men with dementia, and the research, legal issues, and proposed solutions in this Article are, at least prima facie, equally applicable to both men and women, as well as to those in committed gay and lesbian relationships. 
which they are accustomed, their meals are determined by what the facility prepares for them, and they are cared for by relatively unskilled, low-wage workers.

With the aging of the "baby-boomer" population, the incidence of and need for admission to nursing homes is rapidly increasing. ${ }^{8}$ At the same time, dementia in the elderly population in the United States continues to grow, ${ }^{9}$ and most dementia sufferers will ultimately end up in a nursing home. For many persons placed in a facility, whether because of dementia or other reasons, the worst effect of being admitted is the abrupt separation from the constant companionship of a spouse or partner they enjoyed prior to being committed. Logically, care facilities and society in general should do everything possible to foster residents' ongoing relationships with spouses or partners even in the face of the need for institutionalization. Although some persons with dementia may at times even forget to whom they are married, or with whom they have shared a committed relationship, dementia is not a static condition. Dementia is a dynamic disorder with many persons with dementia being lucid during the day but deteriorating in the evening as they become tired. ${ }^{10}$ Others may demonstrate varying patterns of lucidity. A resident with dementia might have regular or intermittent, deeply meaningful connections with others, especially those with whom they have shared the most intimate of relationships.

There is convincing evidence that persons in nursing homes, even persons with dementia in its later stages, benefit physically, mentally, and emotionally from close contact with loved ones, including conversation, touch, hugs and embraces, kissing, and sex. ${ }^{11}$ Nevertheless, nursing homes often discourage ongoing intimate relationships because of logistical, financial, and other considerations. For example, it takes more resources to guarantee residents private space within which they can engage in intimate activities. Consequently, there may be financial incentives for facilities to discourage sexual activities by their residents with dementia. Citing incapacity for residents with dementia to consent to intimate contact, most nursing homes have been reluctant to allow them to have intimate encounters out of a fear of subsequent legal action being taken against them by family members. ${ }^{12}$

There is a growing movement among advocates for the rights of persons in nursing homes, including those with dementia, who are not typically able to

8. See infra Part II.

9. 2015 AlZHEIMER's Disease FACtS AND Figures, supra note 5, at 16.

10. Arias, supra note 5, at 139 .

11. Tenenbaum, supra note 2, at 683; Wendy L. Bonifazi, Somebody to Love, 23 ConTEMP. Long Term Care, 22, 23 (2000); Ramzi R. Hajjar \& Hosam K. Kamel, Sexuality in the Nursing Home, Part I: Attitudes and Barriers to Sexual Expression, 5 J. Am. Med. Directors Ass'N S43, S43 (2004); Tiina-Mari Lyyra \& Riita-Liisa Heikkinen, Perceived Social Support and Mortality in Older People, 61 J. Gerontology: Soc. ScI. S147, S147 (2006).

12. Melissa C. White, The Eternal Flame: Capacity to Consent to Sexual Behavior Among Nursing Home Residents with Dementia, 18 ElDER L.J. 133, 144 (2010); Michael A. Kirtland \& Catherine Anne Seal, Intimacy in the Elder Law Setting, 22 Prob. \& Prop. 34, 36 (2008). 
effectively advocate for themselves, to provide nursing homes with the education and tools to create policies that facilitate ongoing intimate relationships. ${ }^{13}$ The suggested policies often include the use of capacity-to-consent assessment instruments that consider demented residents' desires and need for intimacy. ${ }^{14}$ If incorrectly employed or relied upon as panaceas, however, such assessment instruments can work against residents' rights and best interests.

An example of a facility that has embraced the general ideal of residents' rights and interests in sexual activity is the Hebrew Home in New York. ${ }^{15}$ In 1995, it pioneered a long-term care environment in which residents, including those with Alzheimer's and other forms of dementia, are encouraged to explore their sexuality. ${ }^{16}$ The staff at the Hebrew Home provides private accommodations for intimate encounters between residents, and engages, when appropriate, in discussions with the residents to gauge their emotional reactions to any sexual encounters. ${ }^{17}$ Other nursing homes are beginning to take note and follow the example set by the Hebrew Home. ${ }^{18}$

This Article suggests that nursing homes be required to or voluntarily consider adoption of policies that facilitate all residents' ongoing intimate relationships with a particular focus on residents with dementia. Available literature, and it is considerable, focuses on the rights of long-term care residents with dementia to have intimate relationships with other residents, but largely ignores the perhaps less frequent situation in which a demented resident wishes intimacy with his or her spouse or partner who visits the facility. For example, in 2009 , Evelyn Tenenbaum published a pivotal article exploring the rights and desires of nursing home residents to be sexual beings, but cautioned against the risk of unsafe and abusive relationships that can result. ${ }^{19}$ Tenenbaum explored the hypothetical situation in which a married resident with dementia wishes to engage in an adulterous relationship with another resident, but neglected to address the growing problem of demented married residents being forbidden to have sexual intercourse with their spouses or partners because they are unable to give consent. ${ }^{20}$

13. See, e.g., Laci J. Cornelison \& Gayle M. Doll, Management of Sexual Expression in Long-Term Care: Ombudsmen's Perspectives, 53 GERONTOLOGIST 780, 780-89 (2012); Eliza Gray, Why Nursing Homes Need to Have Sex Policies, Time (Apr. 23, 2015), http:/time.com/3833358/ nursing-home-sex/ [https://perma.cc/9WM3-JKAS]; Paula Spencer Scott, Sex in the Nursing Home, AARPBULL. (June 2015), http://www.aarp.org/home-family/caregiving/info-2015/sex-in-assistedliving-facilities.html [https://perma.cc/A74B-TMJM].

14. Scott, supra note 13.

15. Bryan Gruley, Sex in Geriatrics Sets Hebrew Home Apart in Elderly Care, BloOMBERG (July 23, 2013), http://www.bloomberg.com/news/articles/2013-07-23/sex-in-geriatrics-setshebrew-home-apart-in-elderly-care [https://perma.cc/LUZ7-T372].

16. Id.

17. $I d$.

18. Id.

19. Tenenbaum, supra note 2 , at 683 .

20. Id. 
This Article will (1) discuss the symptoms, manifestation, and prevalence of dementia, with a focus on Alzheimer's disease, ${ }^{21}$ (2) explore the historical approach to determining capacity of long-term care residents to consent to intimacy, ${ }^{22}(3)$ address the health and legal implications of prohibiting or allowing intimacy between a long-term care resident (even if with some degree of dementia) and her spouse or partner, ${ }^{23}(4)$ discuss the application of "critical and experiential interests" (explained below) when determining whether residents should be allowed to engage in intimate activities, ${ }^{24}$ and (5) propose a set of procedural and substantive policies that will allow nursing homes to meet their duties to protect residents' health; (decision-making, geographical, informational, and intimate family or relational) privacy, and other interests (especially the many benefits that flow from appropriate sexual encounters) while at the same time minimizing abuse and exposure to subsequent legal action. ${ }^{25}$ The policies reject the traditional over-reliance on: (1) an idealized paradigm of informed consent designed for typical physician-patient encounters in office or acute hospital settings involving decisions about specific diagnostic procedures and treatment regimens; and (2) a puritanical, counter-intuitive, and unsubstantiated fear that there is a substantial risk that residents will be sexually abused by spouses or partners.

We do not deny that spousal abuse in the general population is a significant problem or that abuse in nursing homes will ever be non-existent, but statistics relating to abuse in the general population cannot be extrapolated to the nursing home context where there is a unique population and specific safeguards-even a traditional antipathy toward intimacy_are in place. Our approach rests on the premise that the risks of stifling intimacy outweigh any benefits of doing so.

\section{Suggested Policies}

Setting forth the policies at the outset will facilitate understanding both of the policies themselves and of the various topics we will explore throughout this Article. Here, then, are our suggested policies. First, all of the substantive and procedural policies should be adopted by state legislatures, imposed through development of the common law (mostly contract and tort), or voluntarily embraced by facility providers (which voluntary adoption once held out to residents and families would become binding as a matter of contract law). ${ }^{26}$

Through a comprehensive-but not impractical or disrespectful-informed consent process, the nursing home must educate residents, families, and staff about the policies and their importance to residents' health and well-being. The nursing home must also provide a space within which residents have enough

21. See infra Part III.

22. See infra Part IV.

23. See infra Part V.

24. See infra Part VI.

25. See infra Parts I, VI.

26. If the written policies included disclaimers preventing liability, then that would make the policies cynical, meaningless exercises. 
privacy should they choose to engage in sexual activities and prohibit practices-such as preventing locking of doors to rooms- that are inimical to sexual privacy.

All residents are presumptively considered competent to give consent to sexual encounters with their spouse/partners. ${ }^{27}$ Consent can be by way of explicit oral or written direction to the facility upon admission; a prior written statement; or, for those without a written statement and unable or unwilling to verbally communicate their wishes, by way of failure to object to sexual advances by their spouse or partner either verbally or physically ("implicit consent"). Given the presumption of family concern with each resident's best interests, we would not require any formalities other than an explicit statement that, if written, must be signed by the resident. ${ }^{28}$ If there is no prior statement or a directive upon admission and the nursing home reasonably has substantial doubts about a resident's competency to consent, it shall arrange or require a competency evaluation by a qualified health care provider. Any such evaluation shall be made using the domain-specific and risk-sensitive approach described in section V.B.4 of this Article.

All residents retain the right to revoke prior explicit or implicit consent by protesting orally or physically regardless of competency. Residents should be encouraged to include their wishes in any specific oral or written statements should they become legally incompetent, and this can include specific directions as to whether sexual activity with their spouses/partners should be continued unless, when able to do so, they refuse such activity either orally or physically. While prior consent can be revoked even by an incompetent resident, a competent resident's prior directive, if any, that intimacy should not continue should she be incompetent, shall not be disregarded. Prior directives can and should include the appointment of a surrogate decision maker who should be able to intervene and make decisions about sexual and other activities in circumstances specified in the policy. The directive can and should also include explicit criteria or approaches the surrogate should use when deciding whether to intervene or to allow continued sexual activities. Finally, because of the obvious conflict of interest, a spouse or partner cannot be appointed as a surrogate.

Unless it becomes obvious - to an appointed surrogate (see above) or a qualified employee of the facility chosen by it to make such judgments- that the resident might lack the capacity to object orally or physically, or if the resident communicates a desire to revoke explicit or implicit consent (see above regarding respecting even incompetent refusal), the facility shall respect and facilitate the resident's and spouse/partner's privacy. If it reasonably appears that the resident might lack capacity and is suffering harm, the appointed surrogate or qualified

27. See generally Maggie L. Syme \& Debora Steele, Sexual Consent Capacity Assessment with Older Adults, 31 ARCHIVES OF ClinICAL NEUROPSYCHOL. 495 (2016), https://academic.oup. com/acn/article-abstract/31/6/495/1726496/Sexual-Consent-Capacity-Assessment-with-Older [https://perma.cc/YU28-73DE].

28. But see Alexander A. Boni-Saenz, Sexual Advance Directives, 68 Ala. L. REv. 1 (2016) (arguing sexual advance directives are so important that they require particular formalities). 
employee appointed by the facility can request the spouse or partner to sign a document that the resident has not verbally or physically refused to engage in sexual activities. The surrogate or qualified employee shall have access to the resident's medical records. Moreover, staff shall be educated on the state of the art concerning detection of abuse, and they shall be required to use this knowledge and make entries into the medical chart as indicated.

If the spouse or partner refuses to sign such affirmation, sexual activities shall not be allowed. If the spouse or partner does make the required affirmation, the appointed surrogate, or the facility's appointed qualified employee when there is no surrogate, should attempt to stop sexual activities by bringing the matter to court only if the surrogate or qualified employee determines that it in the resident's best interest not to engage in sexual activities. Best interest should be determined by a surrogate, a qualified person appointed by the facility, or the court if the matter goes that far, by considering the resident's past relevant representations, other indications of the resident's critical and experiential interests, and the resident's physical and emotional well-being. The burden of proof shall be upon those arguing that sexual activities are not in the resident's best interest.

Nursing homes shall be subject to fines of $\$ 1000$ and an award of attorney's fees for each violation of these policies. This should not preclude any other remedies. It is also noteworthy that the nursing home and any surrogate appointed by the resident or the nursing would stand in fiduciary relationship to each resident, thus subjecting them to liability for failure to fulfill their duties. ${ }^{29}$

\section{Numbers OF NuRsing Home RESIDENTS}

According to the Centers for Disease Control, in 2014 "there were an estimated . . 1,369,700 current residents in nursing homes, and 835,200 current residents living in residential care communities." ${ }^{30}$ The organization also reported, "Projections estimate that among people who reach age 65 , more than two-thirds will need long-term care services during their lifetime, and they have a $46 \%$ chance of spending time in a nursing home." ${ }^{31}$ The Administration on Aging estimates that the population of persons sixty-five and older will increase to $54,804,470$ in $2020 ; 72,091,915$ in $2030 ; 81,238,391$ in 2040 ; and $88,546,972$ in $2050 .^{32}$ In short, the number of persons in nursing homes or residential care communities is considerable and will experience explosive growth in the decades ahead.

29. James, supra note 3, at 434-35.

30. CTR. FOR Disease CONTROL, supra note 7, at 34 (citations omitted).

31. Id. at 3 .

32. Aging into the 21st Century, Admin. On Aging, Admin. For Community Living, U.S. DEP'T HEALTH \&HUM. SERVs. (May 31, 1996), https://aoa.acl.gov/Aging_Statistics/future_growth/ aging21/aging_21.aspx [https://perma.cc/U234-CNMP]. 


\section{DEMENTIA}

\section{A. Diagnosis and Staging of Dementia}

As dementia, and especially Alzheimer's disease, ${ }^{33}$ becomes increasingly prevalent in the United States, nursing home administrators, caregivers, and families have even more need to develop a better understanding of the disease and its impact on the sufferer.

Here, this Article will discuss diagnosis and staging very generally, while in a separate subsection below, the Article will discuss some specific instruments that are used to diagnose capacity to consent. ${ }^{34}$ The National Institute on Aging and the Alzheimer's Association have published recommendations for diagnosing the progression of Alzheimer's disease, including Preclinical Alzheimer's Disease, Mild Cognitive Impairment (MCI), and Dementia Due to Alzheimer's Disease. ${ }^{35}$ It is during this last stage that capacity to consent to sexual activity comes into question.

In the Preclinical Alzheimer's Disease stage, individuals have not yet developed significant noticeable symptoms such as memory loss, but develop measurable changes in the brain. ${ }^{36}$ Biomarkers may be present in the cerebrospinal fluid or blood. ${ }^{37}$

Individuals with MCI develop mild but measurable changes in thinking abilities that are noticeable to the affected individual and to his or her family and friends, but such changes do not affect the individual's ability to carry out everyday activities. ${ }^{38}$ During the MCI stage, individuals are often told they are "overly worried" and that they still "function very well," or that they have "normal forgetfulness related to aging." 39 Individuals with MCI are often reassured that "forgetting something is normal when you age. Forgetting the name of your grandchild once is normal, as is forgetting a card in a game of bridge once in a while." 40

Unlike the "normal forgetfulness" observed in MCI, Dementia Due to Alzheimer's Disease is characterized by quite noticeable changes in memory, thinking and behavior that, unlike MCI, impair a person's ability to function in daily life. $^{41}$

33. See James, supra note 3 , at 409 .

34. See infra Part IV.

35. 2015 AlZheimer's Disease FACtS AND Figures, supra note 5, at 13.

36. $I d$.

37. $I d$.

38. Id.

39. Yvonne Cuijper \& Harro van Lente, Early Diagnostics and Alzheimer's Disease: Beyond 'Cure' and 'Care,' 93 Tech. Forecasting Soc. Change 54, 62 (2015).

40. Id.

41. 2015 Alzheimer's Disease Facts And Figures, supra note 5, at 14. 


\section{B. Prevalence of Dementia}

There are over five million persons in the United States over the age of sixtyfive with Alzheimer's disease. ${ }^{42}$ This equates to one in nine people over age sixtyfive who are diagnosed with Alzheimer's. ${ }^{43}$ Additionally, approximately one-third of people over age eighty-five have Alzheimer's disease. ${ }^{44}$ A large segment of the American population-known as the "baby-boomer" generation-has begun to reach age sixty-five and older, when the risk for developing Alzheimer's and other dementias is greater. ${ }^{45}$ Due to advances in medicine and medical technology, as well as social and environmental conditions, the number of Americans surviving into their eighties and beyond is expected to grow dramatically. ${ }^{46}$ The incidence of Alzheimer's disease in persons over age eightyfive is predicted to increase accordingly ${ }^{47}$ (see Figure 1). ${ }^{48}$

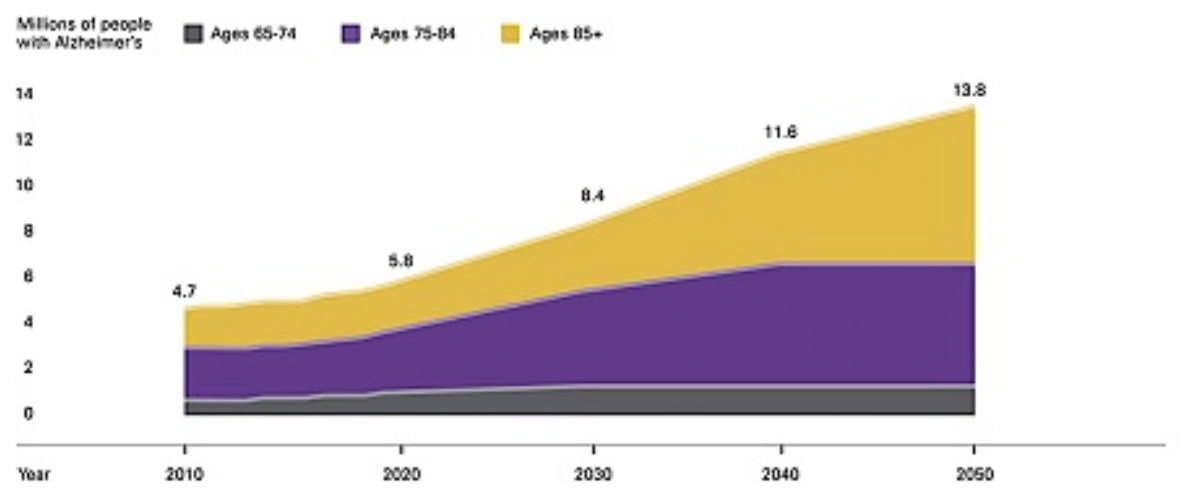

Figure 1: Projected Number of People Age 65 and Older (Total and by Age Group) in the U.S. Population with Dementia

42. Id. at 16 (explaining, "The estimated number of individuals age 65 and older with Alzheimer's disease comes from a recent study using the latest data from the 2010 U.S. Census and the Chicago Health and Aging Project (CHAP), a population-based study of chronic health diseases of older people. National estimates of the prevalence of all forms of dementia are not available from CHAP, but are available from other population-based studies including the Aging, Demographics, and Memory Study (ADAMS), a nationally representative sample of older adults. Based on estimates from ADAMS, 14 percent of people age 71 and older in the United States have dementia.").

43. Id at 9 .

44. Id.

45. Id. at 23 .

46. Id.

47. Id.

48. Id. at 22 . 


\section{Dementia in Nursing Homes}

As the prevalence of dementia continues to rise, the incidence of dementia, and more specifically Alzheimer's disease, in nursing homes increases correspondingly. In 2010, forty percent of residents in assisted living facilities (housing that includes services to assist with everyday activities, such as medication management and meals) and in residential care facilities had Alzheimer's disease and other dementias. ${ }^{49}$ Of all Medicare beneficiaries age sixty-five and older with Alzheimer's disease and other dementias, thirtyone percent live in a nursing home.$^{50}$ Of all Medicare beneficiaries residing in a nursing home, sixty-four percent have Alzheimer's disease and other dementias. ${ }^{51}$ Sixty-eight percent of residential care facilities use a standardized tool to screen residents for cognitive impairment before or at admission. ${ }^{52}$

\section{Sexuality in Nursing Homes Facilitates Residents' Health \& Well-Being}

Despite what looks like a puritanical reticence among Americans to discuss, or even consider, the sexuality of our aging parents and grandparents, ${ }^{53}$ it is time that we as a society accept that "[s] exuality is an integral part of the personality of everyone: man, woman and child; it is a basic need and aspect of being human that cannot be separated from other aspects [of] life." ${ }^{\text {5 }}$ The World Health Organization discusses sexuality in the global context, noting,

[A] central aspect of being human throughout life encompasses sex, gender identities and roles, sexual orientation, eroticism, pleasure, intimacy and reproduction. Sexuality is experienced and expressed in thoughts, fantasies, desires, beliefs, attitudes, values, behaviors, practices, roles and relationships .... Sexuality is influenced by the interaction of biological, psychological, social, economic, political, cultural, legal, historical, religious and spiritual factors. ${ }^{55}$

Notwithstanding a decrease in sexual activity as people age, many older adults still experience active sex lives. ${ }^{56}$ A 2007 New England Journal of Medicine study reported that, of respondents ages sixty-five to seventy-four years old, fifty-three percent reported being sexually active with a partner within the

\section{Id. at 51 .}

50. Id.

51. Id.

52. Id.

53. Elizabeth Hill, We'll Always Have Shady Pines: Surrogate Decision-Making Tools for Preserving Sexual Autonomy in Elderly Nursing Home Residents, 20 WM. \& MARY J. WOMEN \& L. 469,470 (2014).

54. Id. at 473 .

55. Defining Sexual Health, Wordd HeAlth ORG., http://www.who.int/reproductivehealth/ topics/sexual_health/sh_definitions/en/[https://perma.cc/32FY-4SQS] (last visited Mar. 11, 2017).

56. Kenney F. Hegland \& Robert B. Fleming, New Times, New Challenges: Law AND AdVice for SAVVy SENiors AND Their FAMilies 101 (2009). 
previous twelve months, of which sixty-five percent reported engaging in sexual activity with a partner at least two to three times per month. ${ }^{57}$ For respondents ages seventy-five to eighty-five, twenty-six percent reported being sexually active, of which fifty-four percent reported participating in sexual activity with a partner at least two to three times per month. ${ }^{58}$

In the nursing home setting, elderly residents may find that "sexuality comes in many forms and can have many meanings. ${ }^{59}$ For some, it is an important form of expression when other forms have been lost." ${ }^{60}$ The human need for physical connection, affection, and intimacy is not limited to only those capable of expressing consent; rather it "extends beyond [a person's] cognitive status." 61 As an author on elder-care planning notes:

Sex is always more than sex. For the elderly it is a statement of continued involvement with life, a source of emotional support, and a validation of self-worth. It may not even result in orgasms. It can be simply caresses and gentle touching. Self-help manuals abound, and many describe techniques and approaches to sex that are more elder-friendly. ${ }^{62}$

Family members may struggle to fully grasp and embrace these concepts of autonomy and personhood as they relate to sexual expression in the elderly. An adult family member is often the one who makes the decision to place a parent in a nursing home. At this stage, adult children of aging parents may develop paternal attitudes toward their parents, and subsequently interpret sexuality in their elderly parent as they would a pre-teen in a sexual situation. ${ }^{63}$ The amount of influence the adult child is forced to assume during the transition of a parent to nursing home care may extend to include the perceived need to make decisions for the parent throughout the duration of the parent's residency, including decisions about the parent's sexuality. ${ }^{64}$ Although this burden may be ameliorated to a degree by facilities like the Hebrew Home who encourage and facilitate open communication about sexual activity among its residents and their families, more conservative facilities may exert great influence on the children of residents, especially ones with dementia, to discourage and monitor the sexual activity of their parents. ${ }^{65}$ As families assume a greater role in monitoring and controlling the

57. Stacy Tessler Lindau et al., A Study of Sexuality and Health Among Older Adults in the United States, 357 New Eng. J. Med. 762, 766 (2007).

58. Id.

59. Hill, supra note 53, at 474.

60. $I d$.

61. Id.

62. Hegland \& Fleming, supra note 56.

63. Gayle Appel Doll, Sexuality \& Long-Term Care: Understanding and Supporting the NeEds OF Older Adults 88 (2012).

64. $I d$.

65. See Lauren Breland, Lost Libido, or Just Forgotten? The Legal and Social Influences on Sexual Activity in Long-Term Care, 38 LAw \& Psychol. REv. 177, 182 (2014) (“Because sexual relationships involving demented adults raise serious issues of consent and potential abuse, most 
residents' sexual activities with the aim of protecting the resident from potential harm, they risk diminishing the residents' sexual autonomy. ${ }^{66}$

Obviously, sexuality in the older population does not get checked at the door when one enters a nursing home. ${ }^{67}$ Despite society's tendency to perceive older people's sexual behaviors as abnormal or problematic, the reality is that many older people continue to engage frequently in sexual activity. ${ }^{68}$ This activity includes intercourse and masturbation, which are generally considered "normal" in younger people. ${ }^{69}$ Although society may consider this behavior problematic, numerous studies show that sexual intimacy is beneficial for both physical and mental health in the elderly. ${ }^{70}$

As individuals age, their fear of losing a spouse or partner increases, leading to a greater need for reassuring physical contact. ${ }^{71}$ Although the frequency of sexual intercourse in the general population decreases with age, the touching, stroking, and hugging associated with sexual expression is a natural part of older adults' lives. ${ }^{72}$ Furthermore, physical contact contributes to feelings of self-worth and confirms a sense of belonging and togetherness. ${ }^{73}$ In the nursing home environment, physical sexual contact can "relieve depression and physical pain, promote health and healthy self-images, provide safe exercise, and prevent social disengagement." ${ }^{74}$ This is no less true for the resident with dementia. In fact, physical contact has been shown to be an important method for communicating

long-term care facilities would rather err on the side of safety by barring all sexual activity when capacity to consent is questionable."); Syme \& Steele, supra note 27, at 496.

66. Syme \& Steele, supra note 27, at 496.

67. Gayle Appel Doll, Sexuality and Long-term Care: Do They Mix?, AgIng Today, Jan.Feb. 2013, at 1 .

68. Tenenbaum, supra note 2, at 683; see also Andrew Casta-Kaufteil, The Old and the Restless: Mediating Rights to Intimacy for Nursing Home Residents with Cognitive Impairments, 8 J. MED. \& L. 69, 72 (2004).

69. Alexander Warso, Something Catchy: Nursing Home Liability in the Senior Sexually Transmitted Disease Epidemic, 22 ELDER L.J. 491, 498 (2015).

70. Doll, supra note 67; see also Casta-Kaufteil, supra note 68; Lindau et al., supra note 57; Tenenbaum, supra note 2, at 638; Rob Stein, Elderly Staying Sexually Active, WAsH. Post (Aug. 23, 2007), http://www.washingtonpost.com/wp-dyn/content/article/2007/08/22/ AR2007082202000.html [https://perma.cc/X89M-T97Q]; C.G. Ballard et al., Sexual Relationships in Married Dementia Sufferers, 12 InT'L J. Geriatric Psychiatry 447, 450 (1997); Lyyra \& Heikkinen, supra note 11.

71. Stephanie L. Tang, When "Yes" Might Mean "No": Standardizing State Criteria to Evaluate the Capacity to Consent to Sexual Activity for Elderly with Neurocognitive Disorders, 22 ELDER L.J. 449, 458-59 (2015).

72. Tenenbaum, supra note 2 , at 683 .

73. Id.

74. Bonifazi, supra note 11 , at 22-23. 
with dementia patients, ${ }^{75}$ and a lack of intimacy significantly reduces their life expectancy. ${ }^{76}$

The policies we recommend apply to all nursing home residents because all nursing home residents, even the healthiest ones, face challenges to their rights. We focus on residents with dementia because we believe that they face the greatest challenges.

\section{Historical Approach to Determining CAPACity of Demented NURSING HOME RESIDENTS TO CONSENT TO INTIMACY}

Nursing homes have historically taken the position that their duty of care to residents requires that, in some quasi-paternalistic view, they err on the side of protecting the "vulnerable" resident from harm. ${ }^{77}$ Over-blown fear of lawsuits from family members and of criminal liability for encouraging sexual activity that may be interpreted as abuse, influences administrators' judgment when weighing the risks of whether to promote or restrict sexual expression. ${ }^{78}$ Resident sexuality has been medicalized into the framework of supervised informed consent, as evidence by the regular adoption of formalized capacity instruments such as the Appelbaum-Grisso criteria. ${ }^{79}$ Medicalization of sexuality, however, blurs the lines between a nursing home's duty of care to the resident and the exercise of social control over the resident. ${ }^{80}$ Medicalization of a resident's sexuality supports the nursing home's perception that persons with dementia need protection from their own impaired memory and judgment. ${ }^{81}$ There is, however, a strong argument that personhood involves the "dignity of risk." 82 Persons with dementia, like any other person, have the right to subject themselves to a reasonable amount of harm. ${ }^{83}$ Quoting Nay, Tarzia et al. argues, "We cannot eliminate risk without eliminating the person. Life is a risk. It is through struggling and overcoming challenges and taking risks that we become fully human." ${ }^{84}$ Tarzia further argues that sexually active persons face risks throughout their lives, and "we should not confuse a bad or unwise decision with incompetence. Seeking to 'protect' individuals with dementia by not allowing them to express their sexual needs, thereby stifling their

75. Hajjar \& Kamel, supra note 11.

76. Lyyra \& Heikkinen, supra note 11.

77. Laura Tarzia et al., Dementia, Sexuality, and Consent in Residential Aged Care Facilities, J. Med. Ethics (2012), at 3, http://doi:10.1136/medethics-2011-100453.

78. Syme \& Steele, supra note 27 , at 496 .

79. Id.

80. See generally Carole Archibald, Sexuality and Dementia: The Role Dementia Plays When Sexual Expression Becomes a Component of Residential Care Work, 4 AlzHEIMER's CARE Q. 137 (2003).

81. Tarzia et al., supra note 77 .

82. Id

83. Syme \& Steele, supra note 27 , at 496.

84. Tarzia et al., supra note 77 (quoting Rhonda Nay, The Dignity of Risk, AustL. Nursing J., Apr. 2002, at 33). 
autonomy and personhood, is a far greater failure of duty of care. ${ }^{95}$ Herein lies the challenge of achieving balance between autonomy and risk. ${ }^{86}$

Organizations that ignore or discourage sexual expression and activity in residents with dementia may actually be stifling their residents' personhood and autonomy. ${ }^{87}$ As the American Association on Intellectual and Developmental Disabilities ("AAIDD") noted in its position statement, "People with intellectual disabilities and/or developmental disabilities, like all people, have inherent rights. These rights and needs must be affirmed, defended, and respected." 88 AAIDD also posits, "Every person has the right to exercise choices regarding sexual expression and social relationships. The presence of an intellectual or developmental disability, regardless of severity, does not, in itself, justify loss of rights related to sexuality." 89 Therefore, true person-centered care must recognize and support the sexual needs of the nursing home person with dementia, despite any inconvenience, unpleasantness, or logistical challenges it presents. ${ }^{90}$

\section{Legal Implications of Prohibiting or Allowing Intimacy Between a Demented Long-Term Care Resident and Her Spouse/Partner}

\section{A. Civil and Criminal Law Generally}

We have explained that empirical research has clearly demonstrated how relationships, including sexual intimacy, are vital to residents' health and longevity. Conversely, the loss of relationships can be devastating, furthering an elderly resident's withdrawal into a cocoon of nothingness. One only needs to visit a typical nursing home and hear the cries or see the desperation in the eyes of many residents, even if given adequate food, housing, and general care. From the perspective of a non-resident spouse or partner who has sexual appetites, noncooperation by the facility can be an incentive to visit less often, seek sexual satisfaction elsewhere, and even cut off contact with the resident.

Unfortunately, there is little risk to a facility that fails to cooperate. Depending on the facts, there are theoretical causes of action for vindication of residents' rights such as negligence per se (based on statutes and regulations concerning residents' rights), negligence, breach of contract, invasion of privacy, and intentional infliction of emotional distress. Any experienced attorney knows, however, that such suits are of weak legal foundation because of difficulties of showing "fault," causation, and damages sufficient to justify suit. Our research revealed only one case (discussed below) that was based on a claim against a provider or facility for "wrongdoing" associated with the resident's sexual life,

85. Id.

86. Syme \& Steele, supra note 27 , at 496.

87. Id.

88. Sexuality: Joint Position Statement of AAIDD and The Arc, Am. Ass'N OF INTELL. Developmental Disabilities, http://aaidd.org/news-policy/policy/positionstatements/sexuality\#.V1R1BdbaQpY [https://perma.cc/VX63-MEF2] (last visited Mar. 9, 2017).

89. Id. (emphasis added).

90. Tarzia et al., supra note 77. 
and the plaintiff lost on summary judgment because of failure to prove damages. ${ }^{91}$ A provision for fines and attorneys' fees perhaps would alter this dire situation.

Without such legislation it is, again, very difficult for residents to vindicate their rights, and the opposite side of the coin is that nursing homes face a low risk of civil or criminal liability regardless of whether they take proper steps to protect their residents' rights. Nevertheless, nursing home administrators face at least a difficult moral decision when weighing applicable laws that address resident rights, state and federal laws related to resident safety and privacy, and criminal laws designed to protect the resident from assault and abuse. In 1987, the United States Congress enacted the Federal Nursing Home Reform Act (the "Act") that ensures dignity, choice, and self-determination for nursing home residents. ${ }^{92}$ The Act also requires nursing homes to recognize residents' right to "associate and communicate privately with persons of his or her choice," as well as the right to be protected from abuse, injury, and neglect. ${ }^{93}$ Additionally, residents in nursing homes certified by Medicare and Medicaid are granted-by federal law-the right to privacy, including full visual and auditory privacy. ${ }^{94}$

These and related federal and state statutory provisions and the possibility of the common law of privacy expanding by incorporating constitutional rights by way of analogy are the sources of residents' rights to decision making, geographical, informational, and intimate family or relational privacy of which we speak in this Article. ${ }^{95}$

91. Belinky v. Drake Ctr., Inc., No. C-980634, 1999 WL 445689, at*3 (Ohio Ct. App. June 30, 1999).

92. Residents' Rights, Nat'L Long-Term Care Ombudsman Res. Ctr., http:// ltcombudsman.org/issues/residents-rights [https://perma.cc/RCN5-UAKF] (last visited Nov. 28, 2015).

93. White, supra note 12, at 144.

94. Kristine S. Knaplund, The Right of Privacy and America's Aging Population, 86 DENVER U. L. REV. 439, 442 (2009).

95. See, e.g., 45 C.F.R. $\S \S 160.101-160.552$ (2016); 42 U.S.C. $§ 1395 i-3$ (2012); Publication of the OIG Compliance Program Guidance for Nursing Facilities, 65 Fed. Reg. 14,289 (Mar. 16, 2000); Cruzan v. Dir. Mo. Dep't of Health, 497 U.S. 261, 269-70 (1990) (indicating that right to refuse medical treatment - which includes decision making and bodily integrity - is a special liberty interest); Washington v. Glucksberg, 521 U.S. 702, 720-22 (1997) (indicating that the right to refuse medical treatment meets its stringent test for recognition of fundamental rights); Planned Parenthood of Southeastern Pennsylvania v. Casey, 505 U.S. 833, 878 (1992) (plurality opinion reaffirming right to choose an abortion recognized in Roe v. Wade, 410 U.S. 113, 164 (1973), as an important liberty interest); Washington v. Harper, 494 U.S. 210, 224-25 (1990) (special liberty of prisoner to refuse antipsychotic drugs requires government to, as it did here, meet elevated scrutiny); Griswold v. Connecticut, 381 U.S. 479, 485 (1965) (recognizing privacy right of married couples to choose birth control); Eisenstadt v. Baird, 405 U.S. 438 (1972) (recognizing privacy right of single persons to use contraceptives); Whalen v. Roe, 429 U.S. 589 (1977) (indicating informational privacy regarding use of prescription drugs is a fundamental right or special liberty but not applying strict scrutiny because of supposed insignificant burden placed on the right); Obergefell v. Hodges, 135 S. Ct. 2584 (2015) (recognizing fundamental right to choose sexual 
Nursing homes are faced with potentially conflicting resident rights. Despite compelling arguments in favor of promoting the demented residents' need for sexual intimacy, nursing homes also have a duty to protect vulnerable residents from the potential abuses associated with their freedom of sexual expression. ${ }^{96}$ Preventing or hindering residents' right to sexual activity violates their rights to privacy and freedom of association, whereas promoting their right of sexual expression could conceivably place them at risk of mental or physical abuse or harm (e.g., PTSD, depressive disorders, sexually transmitted diseases). ${ }^{97}$ Specifically, between married residents and their spouses, the issue of spousal sexual assault has become an issue of recent legal consideration. ${ }^{98}$

The reality is that the greater risk-which is still quite low-of criminal or civil liability is for failing to protect residents from alleged sexual abuse. Most United States jurisdictions define consent in the context of sexual intimacy in juxtaposition to lack of consent. ${ }^{99}$ Lack of capacity to consent is considered as nonconsent. ${ }^{100}$ Consequently, sexual activity by married residents deemed to lack capacity to consent could conceivably result in the commission of a criminal act by their spouses. ${ }^{101}$ This, however, is a false dichotomy because logically there is a significant grey zone that exists between overt consent and lack of consent filled with misinterpretations of behavior, verbal or otherwise. Consequently, from a scientific perspective the measurement of consent has a very high error rate that is seemingly inconsistent with conviction under the criminal standard of proof.

In early American law, rape could not be committed by one's spouse. ${ }^{102}$ Now, however, nearly every state has statutory language that addresses marital rape, most of which is designed to protect victims of domestic violence. ${ }^{103}$ Because some authorities insist that consent is limited to active affirmation and given the wording of some laws, demented residents who are unable to affirmatively communicate consent might be presumed to withhold it. ${ }^{104}$ For example, under Colorado's Unlawful Sexual Behavior statutes, "a current or previous relationship shall not be sufficient to constitute consent." 105 The statute further includes in its definition the provision that sexual assault occurs when "the actor

partners); Skinner v. Oklahoma, 316 U.S. 535 (1942) (recognizing right to marry); Moore v. City of E. Cleveland, 431 U.S. 494 (1977) (recognizing right of blood relatives to live together); Zablocki v. Redhail, 434 U.S. 374 (1978) (recognizing right to marry); Myer v. Nebraska, 262 U.S. 390 (1923) (recognizing right to control upbringing of children).

96. White, supra note 12.

97. Id.

98. See, e.g., infra Part V.C case law discussion.

99. Kirtland \& Seal, supra note 12, at 36.

100. Id.

101. Id.

102. Id.

103. Id.

104. See id.

105. Colo. Rev. Stat. § 18-3-401 (2016) (emphasis added). 
knows that the victim is incapable of appraising the nature of the victim's conduct." ${ }^{106}$ Although designed to protect individuals from nonconsensual marital relations and forced sexual intercourse when the victim has been rendered incapacitated by, say, drugs or alcohol, a prosecutor could conceivably interpret this statement to say that a person married to an individual for a prolonged period of time but now lacking mental capacity could not consent to sexual intimacy with his or her spouse-despite the fact that they were participating in sexual activities that had been typical in their marital relationship for the entire length of the marriage. ${ }^{107}$ Case law demonstrates, however, that some limited mental capacity alone does not negate the possibility that a spouse may still be able to consent to marital sex. ${ }^{108}$ The policies we recommend, if implemented, would virtually eliminate any risk of liability of the nursing home or the spouse/partner. This is particularly true when there is an explicit directive, because, in the absence of extraordinary circumstances triggering a best interests review, the prior consent is sufficient. ${ }^{109}$

\section{B. Determining Capacity to Consent}

The law described in the preceding subsection probably informs nursing home adoption of an idealized conception of informed consent fashioned to fit the traditional one-on-one healthcare provider-patient relationship in office and acute hospital settings, where patients are offered diagnostic and treatment regimens. Nursing homes, moreover, historically have taken a simplistic, overly protective, restrictive approach to assess a demented resident's capacity to consent, determining that any diagnosis of dementia eliminates the resident's capacity to consent to sexual intimacy. Assessment tools such as the Mini-Mental State Examination and the Lichtenberg and Strezepek Competencies Assessment, while acknowledging that capacity to consent is not "all or nothing," rely on overly restrictive criteria to determine capacity. ${ }^{110}$ In practice, many nursing homes embrace policies that violate resident rights in favor of "protecting" them from abuse. For example, some facilities have policies that do not allow residents to lock their doors, allow staff to "knock and enter" without waiting for a response from the resident, actively discourage sexual activity among residents, and negate resident privacy by placing them in semi-private rooms with only a curtain

106. Id. § 18-3-402(1)(b).

107. Kirtland \& Seal, supra note 12 , at 36.

108. See, e.g., Belinky v. Drake Ctr., Inc., 690 N.E.2d 1302, 1307 (Ohio App. 1996).

109. But see Boni-Saenz, supra note 28 (taking the position that there must be affirmative consent, advocating adoption of sexual advance directives that are sufficient for consent only if there is a consensus of consents between the advance directive and the resident's wishes at the time of sexual activity, and citing a Canadian case - R. v. J.A., 2011 SCC 28, [2011] 2 S.C.R. 440, para 66 (Can.) - which refused to accept the idea of prior as opposed to contemporaneous consent to sex). Legislation or common law development would be necessary to guarantee prior directives implemented as a matter of contract law would not be found void as against public policy.

110. Tarzia et al., supra note 77 , at 2 . 
separating room occupants. ${ }^{11}$ Some facilities have gone so far as to place residents in zipper-less jumpsuits, place residents' clothes on backwards, and restrain residents to restrict sexual activity. ${ }^{112}$ When these practices are implemented against residents who are capable of consenting to sexual activity, the duty to protect from harm has overshadowed the duty to protect the residents' privacy and freedom of association. The problem is exacerbated when considered in relation to a demented resident's right to engage in a sexual relationship with his or her spouse or partner who does not have dementia. Additionally, since the risk that family members will object, or even sue the evaluator for not allowing a demented resident to have sex is much less than of wrongfully validating the resident's capacity to consent, evaluators may be incentivized to err on the side of incapacity.

1. The Mini-Mental State Examination.-The Mini-Mental State Examination (MMSE) is a standardized test often used to indicate capacity to consent to sexual activity. ${ }^{113}$ The MMSE analyzes several of the subject's cognitive functions, including memory, language, spatial ability, and set-shifting. ${ }^{114}$ "The test is based on a thirty-point scale, where a higher score indicates greater cognitive functioning. A score of ten or below indicates severe dementia . ..."115 A longterm care facility that relies on the MMSE may determine a resident who "fails" the exam has no capacity to consent, despite other indicators to the contrary, such as non-verbal indications of pleasure or agitation. ${ }^{116}$ Finally, those who use this instrument frequently fail to recognize that the MMSE is a rather simplistic instrument that "does not have any tasks to assess executive functions like tests of the capacity to abstract or to judge a social situation," skills clearly relevant to a decision to engage in sexual activities. ${ }^{117}$

2. The Lichtenberg \& Strezepek Assessment.-Like the MMSE, the competencies assessment developed by Lichtenberg and Strezepek requires that a resident's behavior be consistent with her formerly held beliefs and ignores the effect dementia can have on the resident's current behavior, values, and personality. ${ }^{118}$ For example, in the Lichtenberg \& Strezepek Assessment, the professional clinician is directed to ask if the resident knows who is initiating sexual contact, if the resident can state what level of sexual intimacy they would be comfortable with, if the behavior is consistent with formerly held values and beliefs, and if the resident can describe how they will react when the relationship

111. Knaplund, supra note 94 , at 443.

112. Id.

113. White, supra note 12 , at 150.

114. Id.

115. Id.

116. Id.

117. Martine Simard, The Mini-Mental State Examination: Strengths and Weaknesses of a Clinical Instrument, CANADIAN AlzHEIMER DiseAse Rev. 10, 12 (Dec. 1998).

118. Peter A. Lechtenberg, Handbook of Assessment in Clinical Gerontology 343 (2010). 
ends. ${ }^{119}$ Of particular concern is the limitation on the resident's freedom to choose to have a sexual relationship if she is unable to verbally communicate her responses. ${ }^{120}$ Other assessments have similar limitations.

3. The Appelbaum-Grisso Criteria.-A number of professional groups have adopted capacity assessments that rely on the Appelbaum-Grisso criteria to determine capacity to provide legal consent to medical treatment and research. ${ }^{121}$ These criteria, which have their basis in legal standards, require that an individual "(1) be able to communicate a decision, (2) understand the relevant information, (3) appreciate his or her situation, and (4) be able to rationally manipulate information [(or, to reason)]. " ${ }^{122}$ Although the Appelbaum-Grisso criteria provide valuable information about a person's cognitive deficits, they are insufficient on their own to determine an individual's decision-making capacity. ${ }^{123}$

One of the many challenges associated with using strict criteria capacity assessments, such as the MMSE or Appelbaum-Grisso, to determine capacity is that an individual's capabilities, and subsequent capacity to consent, may not be consistent over time. ${ }^{124}$ Because a person may experience "good" days and "bad" days, clinicians cannot use past or predicted behaviors to evaluate capacity; rather, under these assessments, capacity is determined according to the individuals' capabilities in their current state at the time of the evaluation. ${ }^{125} \mathrm{In}$ other words, a cognitive evaluation only provides a snapshot of the individual's capacity at the time of the evaluation; it cannot determine future or past capacity at any given time ${ }^{126}$ Furthermore, application of the Appelbaum-Grisso criteria to decisions about sex is inappropriate, because, as Lindsay suggests, relationships "do not necessarily form in a structured logical manner. . . [S]ex is not a decision most people make after carefully weighing the pros and cons or the biological implications of their decision." 127

4. The Domain-Specific and Risk-Sensitive Approach.-A recent trend among professional clinicians in conducting capacity evaluations has shifted the focus

119. Id.

120. Doll, supra note 67.

121. Scott Y.H. Kim, Evaluation of CAPACity to Consent to Treatment And Research 65 (2010); see also Laura L. Sessums et al., Does This Patient Have Medical Decision-Making Capacity?, 306 JAMA 420, 422 (2011).

122. Arias, supra note 5, at 143.

123. Sessums et al., supra note 121; see also Doll, supra note 67 , at 1-2 (“[M]aking sound decisions requires an ability to reason and verbally express oneself. This definition would rule out many relationships that seem to offer mutual support."); Tarzia et al., supra note 77, at 2 ("We suggest, therefore, that when it comes to relationships and intimacy, existing capacity assessment frameworks may be fundamentally inappropriate.").

124. Arias, supra note 5, at 142-45.

125. Id. at 139.

126. Id.

127. J. Richard Lindsay, The Need for More Specific Legislation in Sexual Consent Capacity Assessments for Nursing Home Residents: How Grandpa Got His Groove Back, 31 J. LEGAL MED. 303, 314 (2010). 
from clinical diagnoses to assessment of functional and cognitive abilities. ${ }^{128}$ Utilizing a "domain-specific and risk-sensitive" approach, until proven otherwise, the presumption of capacity underlies a person's decision-making capability. ${ }^{129}$ Under this structure, an individual's capacity is evaluated relevant to the context of a specific action or decision. ${ }^{130}$ The domain of a person's capacity is relevant to the cognitive and functional abilities necessary for the specific action or decision. ${ }^{131}$ For example, determination of a person's capacity to manage personal finances may require a different assessment than that used to determine a person's capacity to operate a motor vehicle. An individual may also be assessed on her capacity to weigh the risk versus the potential benefit of an action or decision. ${ }^{132}$ A greater risk associated with the action, compared to the potential benefits, requires a higher level of capacity to make a decision to engage in the action. ${ }^{133}$ For example, an evaluator may determine a patient lacks the capacity to consent to major surgery but maintains sufficient capacity to appoint a proxy decision maker for the same decision. ${ }^{134}$ Consequently, using the domain-specific and risksensitive approach, a diagnosis of dementia alone is not conclusive evidence an individual lacks capacity. ${ }^{135}$ Notwithstanding various statutory laws among different jurisdictions related to lawful capacity to consent, even mental patients who are involuntarily or voluntarily admitted to institutions are presumed to be able to consent unless the state shows them incompetent. ${ }^{136}$

As it applies to a person's capacity to engage in sexual activity with a spouse or partner, the evaluator will need to weigh the long-term care resident's risks associated with continued sexual activity compared with the benefit of maintaining the intimate relationship with her spouse or partner. Once again, in this context, the stringency of capacity review increases with the risks involved. (Perhaps the greater risk is in not allowing sexual activities.) When assessing risk, for example, the evaluator will need to consider if the resident is physically capable of engaging in sexual activity without risk of injury, and whether loss of intimacy with her partner will exacerbate cognitive deterioration. The obvious ramification of the domain-specific and risk-sensitive approach in this context is it requires a case-by-case analysis over a sufficient period of time to account for possible variations in the resident's lucidity. The evaluator's task should be to determine whether, in light of all the considerations delineated, the presumption of patient competency to consent has been overcome.

128. Arias, supra note 5, at 140.

129. Id.

130. Id.

131. Id.; see also Tarzia et al., supra note 77, at 2 ("That different decisions require different levels of capacity is a theory well supported within the literature ....”).

132. Arias, supra note 5, at 141.

133. Id.

134. $I d$.

135. Id. at 140 .

136. See, e.g., Rogers v. Comm'r of Dept. of Mental Health, 390 Mass. 489, 491 (1983). 
It is well established that dementia is defined on a continuum, from preclinical Alzheimer's disease, to mild cognitive impairment manifesting as mild forgetfulness or confusion, to advanced stages of dementia in which the individual may lose the ability to communicate and carry out functions of daily living. ${ }^{137}$ There is no predictability, however, in the reliability of a person's cognitive function within the various stages of dementia. ${ }^{138}$ Carpenter et al., however, found that among married persons "reliability for individuals with dementia was particularly good, which reinforces the theory that dementia does not stop people from making, and continuously assessing, choices regarding intimacy." 139 Stated differently, married persons with dementia are often capable of reliably making good choices regarding sexual intimacy. Because dementia occurs on a continuum, sexual consent by a person with dementia cannot be decided by a one-time, yes or no, determination; rather, it requires an ongoing evaluation of relevant physical, cognitive, and emotional limitations of the resident. ${ }^{140}$ These findings further support the use of case-by-case assessment of each individual's reliability and capacity to consent under a domain-specific and risk-sensitive approach.

\section{Case Law}

Several recent cases are illustrative of the issues faced both by spouses of demented residents and by nursing home administrators. In Belinky v. Drake Center, Inc., an Ohio appeals court held state statutes provide that "one member of the patient's or resident's immediate family, his guardian, physician, or spiritual advisor may visit [the resident] at any time, subject to any rules set forth by home to ensure that such visits will not interfere with the operation of the home." "141 In Belinky a husband sued Drake Center ("Drake"), a nursing home, when it refused to allow him to stay overnight with his wife, who had suffered a stroke and was rendered incapable of providing consent. ${ }^{142}$ The husband and his family members told the nursing home that he did not intend to have sexual relations but merely wished to comfort his wife. ${ }^{143}$ The nursing home told the husband that given "the complex legal environment in which we exist," it "had to protect the rights of its patients and that if he were to molest his wife, she might later regain her competence and sue [the nursing home]."144

The Ohio appeals court affirmed in part and remanded in part, noting in dicta that although the nursing home was acting to protect their resident (the wife) from

137. See 2015 Alzheimer's Disease Facts And Figures, supra note 5, at 11.

138. See generally Brian D. Carpenter et al., Preferences and Life Evaluations of Older Adults With and Without Dementia: Reliability, Stability, and Proxy Knowledge, 22 Psych. \& AgING 650 (2007).

139. Tarzia et al., supra note 77.

140. Syme \& Steele, supra note 27, at 502.

141. 690 N.E.2d 1302, 1308 (Ohio Ct. App. 1996).

142. Id. at 1306 .

143. Id.

144. $I d$. 
possible harm, it did not have adequate grounds for fearing that a concerned and dedicated husband would act adversely to his wife's best interests, and "could have handled the situation in a more effective manner." ${ }^{145}$ On remand, the lower court granted summary judgment against the husband, since he did not provide adequate proof to establish any damages. ${ }^{146}$ Although the husband did not win the case, the appellate court indirectly supported the right of a demented married woman to be visited and cuddled by her spouse at night.

In State v. Johnson, the Wisconsin appeals court ruled videotaped evidence of a husband's sexual intercourse with his comatose wife was inadmissible evidence, as it violated both the husband's expectation of privacy in his wife's nursing home room and his right to exclude others from his wife's room while he was present. ${ }^{147}$ The court further held that despite his wife's inability to give explicit consent, the husband had a reasonable expectation to assume he had permission to be in his wife's room, because the nursing home facility considered him a legitimate guest, and he was there with the facility's full knowledge and consent. ${ }^{148}$ Here also, the court did not address the resident's incapacity to explicitly consent to sex during his overnight visit. ${ }^{149}$ The court found "nonsensical" the State's assertion that he may have had permission to be in her room, but he did not have permission "to sexually assault her;" the husband was not required to offer evidence to that effect. ${ }^{150}$

Belinky and Johnson set the stage for State v. Rayhons, ${ }^{151}$ where an Iowa trial court considered whether a husband had sexually assaulted his wife who had been diagnosed with Alzheimer's disease and became a new resident of a nursing home. ${ }^{152}$ The wife was placed in the nursing home by her daughter following a series of events that led her daughter to believe she was no longer capable of caring for herself without assistance. ${ }^{153}$ Her husband visited her daily, they often sat together holding hands, and they had conversations in which the wife, with lucidity, recalled details about their life, inquired about their ranch, and expressed her dislike of being at the nursing home. ${ }^{154}$ The couple had frequent sexual

145. Id. at 1309 .

146. Belinky v. Drake Ctr., Inc., No. C-980634, 1999 WL 445689, at*3 (Ohio Ct. App. June 30, 1999).

147. See generally 758 N.W.2d 224 (Wis. Ct. App. 2008) (unpublished disposition).

148. Id. ๆ 12.

149. See generally id.

150. Id. ๆ 8 n.2.

151. Arian Schuessler, Jury: Man Not Guilty of Sexually Abusing Wife with Dementia, MiAmI

HERALD (Apr. 22, 2015), http://www.miamiherald.com/news/nation-world/national/article 19263942.html [https://perma.cc/H68H-7PRM].

152. Id.

153. Sarah Kaplan, Former Iowa Legislator Henry Rayhons, 78, Found Not Guilty of Sexually Abusing Wife with Alzheimer's, WASH. Post (Apr. 23, 2015), https://www.washingtonpost.com/ news/morning-mix/wp/2015/04/23/former-iowa-legislator-henry-rayhons-78-found-not-guilty-ofsexually-abusing-wife-with-alzheimers [https://perma.cc/4F39-XVH5].

154. Bryan Gruley, Can a Wife with Dementia Say Yes to Sex?, Bloomberg (Dec. 9, 2014), 
intercourse, and the nursing home staff expressed concern to the resident's daughter that the wife was unable to give knowledgeable consent to the sexual activity. ${ }^{155}$ The nursing home physician conducted a BIMS on the wife and determined she was demented and, therefore, incapable of consenting to sex. ${ }^{156}$ Upon being informed of the doctor's determination, the husband agreed to stop having sex with his wife. ${ }^{157}$ The resident's (wife) daughter, however, was not convinced and had the nursing home place her mother in a semi-private room to discourage inappropriate activity with her husband. ${ }^{158}$ Shortly thereafter, the husband closed the curtain around his wife in order to "get [her] ready for bed." 159 That evening, Mrs. Rayhons' roommate reported to the staff that she had heard "sexual" sounds coming from the resident's bed. ${ }^{160}$

The husband was arrested and charged with sexual assault of his wife. ${ }^{161}$ Under Iowa law, an act is sexual abuse in the third degree if the two parties are not living together as husband and wife and if one person "is suffering from a mental defect or incapacity which precludes giving consent." ${ }^{162}$ Here, again, the court did not specifically address the issue of whether the resident (wife) had the capacity to consent, and the jury acquitted the husband of sexual assault in the third degree. ${ }^{163}$ It remains unclear whether the jury believed the resident was capable of consenting or whether it believed there was insufficient evidence to reach a conviction. These cases demonstrate that, as a matter of law, the issue of whether a demented married resident has the capacity to consent to sexual activity with his or her spouse or partner is still undetermined; however, the limited number of cases that have addressed the issue appear to lean toward either the right of a non-resident to privacy when visiting, or the implicit capacity of the demented long-term care resident to consent to sexual intimacy with his or her spouse. For example, in Drake, the court observed that a caring and dedicated husband was unlikely to do anything to harm his wife. ${ }^{164}$ In Johnson, the court refused to place more weight on the risk of harm to the resident than on the husband's right to privacy, even in a nursing home. ${ }^{165}$ Additionally, the jury's acquittal of the husband in Rayhon showed the court was reluctant to find that the

https://www.bloomberg.com/news/2014-12-09/rape-case-asks-if-wife-with-dementia-can-say-yesto-her-husband.html [https://perma.cc/V9KH-C3G7].

155. Schuessler, supra note 151.

156. Id.

157. Kaplan, supra note 153.

158. Gruley, supra note 154.

159. Id.

160. Id.

161. Id.

162. Schuessler, supra note 151.

163. Id.

164. 690 N.E.2d 1302, 1309 (Ohio Ct. App. 1996).

165. See generally 758 N.W.2d 224 (2008) (unpublished disposition). 
husband had sexually assaulted his wife, even though he admitted to frequent sexual intercourse and there was substantiating physical evidence. ${ }^{166}$

\section{SOCIAL THEORIES AND SOLUTIONS}

Faced with the conflicting duties of ensuring a resident's rights; determining her capacity to consent; and protecting her from potential harm; how should a nursing home navigate this minefield? The following solutions, founded in social theory, are considered and analyzed: (1) advancing sexual directives and sexual powers of attorney, (2) promoting functional consent policies, (3) supporting education for residents, families, and staff, and (4) creating an environment conducive to spouse or partner intimacy.

\section{A. Social Theories-Critical and Experiential Interests}

Character theorists such as Ronald Dworkin posit that individuals create the person they are "by selecting a set of values that are stable over [their] lifetime." 167 Together, these values and the actions they produce, serve to construct a rational lifeplan. ${ }^{168}$ The values one selects are based on critical interests, or identity-defining commitments "chosen by individuals based on what they believe makes their lives meaningful, and the personal attributes that they want to possess." ${ }^{.169}$ Critical interests are judgments created by "the self's ability to reason, its capacity for self-reflection, and its ability to create rational life plans." 170

By contrast, experiential interests such as pleasure, pain, desires, tastes, and emotional reactions are the sensations that people feel. ${ }^{171}$ Examples of experiential interests include sitting in the sun, eating ice cream, or listening to a particular style of music. ${ }^{172}$ Because persons with dementia progressively lose their ability to reason and their ability to formulate and sustain a rational life plan, Dworkin argues that decisions made on behalf of demented persons should be based on precedent autonomy, or the values that mattered to them when they were still able to rationally choose. ${ }^{173}$ Thus, precedent autonomy, argues Dworkin, reflects the values one creates and nurtures while still rational and deciding whom to be. ${ }^{174}$ Therefore, according to Dworkin, the critical interests that form the basis

166. Schuessler, supra note 151.

167. Tenenbaum, supra note 2 , at 701 .

168. Id. at 701-02.

169. Id. at 702 .

170. Id. (citing Allen E. Buchannan \& Dan W. Brock, Deciding for Others: The Ethics of Surrogate Decision Making 163 (1990)).

171. Id.

172. $I d$.

173. Id. at 703 .

174. Id. 
of our person should be respected above the experiential interests that manifest when we are no longer competent. ${ }^{175}$

The policies we have recommended give great weight to critical interests by encouraging explicit oral or, preferably, written directives promulgated either prior to or at admission to a nursing home. The resident is presumed competent and her prior directive or directive upon admission (including possible appointment of a surrogate decision maker who can be given direction how to decide in unaddressed circumstances) controls.

Rebecca Dresser argues, however, that a person's prior values should not control decision making on behalf of a demented person. ${ }^{176}$ A person's values and desires may change to such a degree that it no longer makes sense to base decisions for that person on prior values. ${ }^{177}$ Dresser bases her argument on Derek Parfit's view that personal identity, rather than being an expression of critical interests, is linked to psychological continuity and connectedness of persons' "memories, intentions, thoughts, sensations, beliefs, and desires." 178 According to Parfit, if there is sufficient disturbance in memory or other psychological connectedness due to injury or disease, the individual is "no longer the same person. He or she essentially becomes a new and different self." 179 Consequently, Dresser posits, individuals suffering severe memory loss or other changes in their capacities, needs, or desires - such as occurs with dementia-fundamentally become different persons. ${ }^{180}$ "Basing decisions for demented patients on values they formed when competent would, therefore, be like having unrelated strangers make decisions for them." ${ }^{181}$ Consequently, Dresser and other experiential theorists suggest that demented persons' contemporary preferences-or experiential interests - should control decisions made by others on their behalf, rather than the precedent autonomy-or critical interests-formed when they were competent. ${ }^{182}$

Countering the argument that if Parfit's psychological continuity theory were applied to all incompetent persons, then no advance directive would ever be valid, Dresser argues, "[T]here are different concerns with dementia because it is perhaps the only disease where a person can be content and have pleasurable experiences for a long time between [the onset of dementia] and death." 183 Therefore, the observation of demented residents' pleasurable experiences in nursing home care may be of great value when exercising substituted decision making in their interests. ${ }^{184}$

175. Id.

176. Id. at $705-06$.

177. Id. at 705 .

178. Id. at 706 .

179. Id.

180. Id.

181. Id.

182. Id.

183. Id. at 706-07.

184. Id. at 707 . 
Dresser suggests that rather than relying on values and decisions made by a person before they became demented, nursing homes and families should focus on the present and future experiential interests of the 'new' person, by applying a "best interests" surrogate decision-making test. ${ }^{185}$ The best interests test requires that long-term care facilities "make decisions based on what would benefit the resident the most and cause the least amount of harm." ${ }^{" 186}$ Rather than consider the resident's individual preferences, the best interests test is an objective test that "relies on what a hypothetical average citizen or reasonable person would choose." ${ }^{187}$ Given that sex is so closely integrated with a person's health and longevity, a best interests test should consider the health benefits of sex to the demented resident in addition to other factors. ${ }^{188}$ There are two obvious problems with the best interests test. First is the questionable objectivity of the person who determines what an average or reasonable person would choose. ${ }^{189}$ A conservative caregiver could feasibly determine that a reasonable person would not consent to marital sex if she could no longer give affirmative consent. ${ }^{190}$ Alternatively, a caregiver may feel that the pleasure the resident experiences during sex with a non-demented partner is of more value than any risk of potential abuse. ${ }^{191}$ Secondly, using a reasonable person test robs the resident of her ability to make choices about her personal lifestyle and values. ${ }^{192}$ By elevating the decision maker's values over those specifically identified by the resident, the resident is deprived of liberty, respect, and dignity. ${ }^{193}$

Dresser points out possible problems with Dworkin's "precedent autonomy" approach, and we have noted two significant drawbacks of Dresser's "reasonable person approach." ${ }^{" 194}$ Both the critical interest and the experiential interest theories are further flawed. Neither theory considers that until the latest stages of dementia-when a long-term care resident's incapacity is so severe that she can no longer form critical interests or express experiential interests-a demented resident is capable of complicated thought and is able to preserve a sense of what she values "beyond mere experiential pleasure." 195 Even residents with severe dementia have been shown to demonstrate a stable set of values through their behavior. For example, a demented resident whose behavior expresses a desire to help others manifests a critical interest value of service to others. ${ }^{196}$ For this reason, incorporating critical and experiential interests into both domain-specific

185. Id.

186. Id. at 708 .

187. Id.

188. See discussion in footnotes $210-14$ and accompanying text.

189. Tenenbaum, supra note 2 , at 708.

190. Id. at 709 .

191. Id.

192. Id.

193. Id.

194. Id. at 703-06, 708-09.

195. Id. at 710.

196. Id. at 711. 
and risk-sensitive functional competence assessments, ${ }^{197}$ and a best interests surrogate decision-making approach when the resident is incompetent makes much sense. That is what our policies do. The functional competence approach is described below. ${ }^{198}$ The best interests test we recommend differs from Dresser's reasonable person approach because it calls for some consideration of both the resident's critical and experiential interests. Once again, our policies invoke the best interests test for surrogate decision making only if the resident has been shown incompetent under the functional competence approach. It states:

Best interests should be determined by a surrogate, a qualified person appointed by the facility, or the court if the matter goes that far, by considering the resident's past relevant representations, other indications of the resident's vital and experiential interests, and the resident's physical and emotional well-being. The burden of proof shall be upon those arguing that sexual activities are not in the resident's best interests.

\section{B. Advance Directives and Sexual Powers of Attorney}

Advance directives and powers of attorney that create an agency relationship empowering a third party to act as attorney-in-fact on one's behalf have been powerful tools used for centuries in business and estate planning. ${ }^{199}$ Advance directives give the resident the power to control her destiny while she is competent and focused on her future wishes. The directive can also contain a power of attorney that appoints a surrogate decision maker and, if desired, decision-making criteria to be used by that surrogate. ${ }^{200}$ A power of attorney may be broad or narrow in scope and grants the agent authority to act in accordance with the principal's known expectations or, if not known, the principal's best interest as broadly defined in the recommended policies. ${ }^{201}$ At the time the power of attorney is created, the principal must be competent, and the agreement generally must be in writing and signed by the principal. ${ }^{202}$ Whereas, under common law a power of attorney terminates upon incapacitation of the principal, a properly drafted durable power of attorney survives the principal's incapacitation. ${ }^{203}$ Generally, a power of attorney is created either to manage the

197. See discussion "The Domain-Specific and Risk-Sensitive Approach"; see also Tenenbaum, supra note 2, at 711 (explaining a functional competence assessment allows factfinders to determine that a person is incompetent in some areas but not others).

198. See infra Part VI.C.

199. Hill, supra note 53, at 486; see also Evelyn Tenenbaum, Sexual Expression and Intimacy Between Nursing Home Residents with Dementia: Balancing the Current Interests and Prior Values of Heterosexual and LGBT Residents, 21 TemP. Pol. \& Civ. RTs. L. Rev. 459, 470 (2012).

200. Hill, supra note 53, at 489.

201. Id. at 486; Boni-Saenz, supra note 28 , at 14 (claiming the idea of a sexual advance directive is entirely novel and adopting a scheme of a consensus of consents that seems to make the advance directive almost useless in many situations).

202. Hill, supra note 53, at 486.

203. Boni-Saenz, supra note 28 , at 11-12. 
principal's financial affairs or to make healthcare decisions on the principal's behalf. ${ }^{204}$

Under the doctrine of precedent autonomy, ${ }^{205}$ extending the healthcare power of attorney to include the authority to make decisions about the principal's sexual activities may bridge the gap between a nursing home resident's rights and the facility's concerns about the resident's capacity to consent to sexual activity. ${ }^{206}$ The Uniform Health-Care Decisions Act (1993) states an "adult or emancipated minor may execute a power of attorney ... which may authorize the agent to make any health-care decision the principal could have made while having capacity., ${ }^{207}$ From a legal standpoint, a sexual power of attorney or advance directive may provide an essential element of a consent defense to sexual assault or battery. ${ }^{208}$ This may be especially true when the demented resident's current experiential interests align with her past critical interests. ${ }^{209}$

Sex is closely associated with health and longevity. Among the many health benefits of sex, it has been shown to decrease the risk of cancer, ${ }^{210}$ reduce the risk of heart disease, ${ }^{211}$ help control obesity, ${ }^{212}$ and reduce pain. ${ }^{213}$ Because sex is so closely integrated with the health of an individual, even to the point of affecting a person's physical longevity and mental and psychological health, ${ }^{214}$ existing frameworks of health care powers of attorney should provide suitable tools for developing a sexual power of attorney, incorporating a nursing home resident's sexual preferences should she become incapacitated. Our recommended policies would make the possibility explicit.

To provide the agent with as much direction as possible, the power of attorney should be accompanied by an advance directive that includes specific instructions about the principal's desires and expectations should she no longer be able to make decisions for herself due to incapacity. ${ }^{215}$ Under the advance

204. Id. at 4 .

205. Tenenbaum, supra note 2 , at 703 .

206. Hill, supra note 53, at 486.

207. National Conference of Commissioners on Uniform State Laws, Uniform Health-Care Decisions Act $\S 2$ (b) (1993).

208. Boni-Saenz, supra note 28 , at 14 .

209. Id. at 27.

210. Shaoni Bhattacharya, Frequent Ejaculation May Protect Against Cancer, NEw SCIENTIST (Apr. 6, 2006), http://www.newscientist.com/article/dn4861-frequent-ejaculation-may-protectagainst-cancer.html\#.UcjaAj771Qw [https://perma.cc/7KWG-5BXH].

211. See generally Susan A. Hall et al., Sexual Activity, Erectile Dysfunction, and Incident Cardiovascular Events, 105 AM. J. CARDIOLOGY 192 (2010) https://www.ncbi.nlm.nih.gov/ pmc/articles/PMC2824175/ [https://perma.cc/9ZXY-65CP].

212. Krista Casazza et al., Myths, Presumptions, and Facts about Obesity, 5 New England J. MED. 446, 449 (2013).

213. Yu. V. Uryvaev \& G. A. Petrov, Extremely Low Doses of Oxytocin Reduce Pain Sensitivity in Men, 122 Bull. Experimental Biology \& Med. 1071, 1071-1073 (1996).

214. See discussion in supra Part III.D.

215. Hill, supra note 53, at 486. 
directive, the principal may, for example, express a desire to continue a relationship of sexual intimacy with a current spouse or partner or specify that if unable to recognize a current spouse or partner, the principal should be free to enter into new relationships with other residents by way of physical pursuit, reaching out, and submission to another person. ${ }^{216}$

A sexual power of attorney is not without challenges. First, state law may limit the scope of powers of attorney. ${ }^{217}$ This is one reason why it would be preferable to implement our policies through legislation. Second, unlike granting decision-making power to one's son for the management of a bank account, or asking one's daughter to decide whether to maintain life support, selecting a surrogate decision maker for one's sexual expectations and preferences may prove difficult at best. ${ }^{218}$ Finally, there are moral and ethical elements to consider, such as whether the person who occupies a body upon execution of the advance directive is in fact the same "person" who occupies the body after dementia has taken over. ${ }^{219}$

What a person believes she will want for herself when no longer competent to communicate her wishes may not align with her post-dementia beliefs, desires, and values. Advance directives were originally developed to deal with conditions involving loss of consciousness, such as occurs in a coma or acute persistent vegetative state. ${ }^{220}$ In this condition, a person's interests would not develop over time; rather, the person would simply become unable to communicate her interests. ${ }^{221}$ More recently, however, advance directives are being used to direct decision making for conditions such as Alzheimer's disease, other dementias, and strokes. $^{222}$ This use of advance directives for residents with long-term care disabilities, just as in the case of coma or persistent vegetative state, raises the issue of whether "someone in any rational way [can] irrevocably determine well in advance what they will want in a situation they have never experienced before." 223

Consider, for example, a well-publicized story involving U.S. Supreme Court Justice Sandra Day O'Connor and John O'Connor, her husband of more than fifty years. ${ }^{224}$ They married in 1952 and, nearly forty years later, John was diagnosed with Alzheimer's disease in $1990 .^{225}$ In 2005, Justice O'Connor resigned from the Supreme Court to care for her husband and placed him in an assisted living

216. Id. at 489 .

217. Id. at 488 .

218. Id.; see also Tenenbaum, supra note 2, at 704.

219. Tenenbaum, supra note 2 , at 705.

220. Tenenbaum, supra note 199 , at 471.

221. Id.

222. Id.

223. Id. (quoting Daniel Callahan, Terminating Life-Sustaining Treatment of the Demented, 25 Hastings Ctr. ReP. 25, 27 (1995)).

224. Knaplund, supra note 94 , at 439.

225. Id. 
facility. ${ }^{226}$ In 2007, John O'Connor fell in love with another resident. ${ }^{227}$ Justice O'Connor responded to the news of her husband's new romance by expressing that she was glad he was happy. ${ }^{228}$ But what outcome would have resulted if John had created an advance directive expressing his expectation that he should remain faithful to his wife and continue having a sexual relationship with her only? It is reasonable to believe that after nearly half a century of marriage and faithful devotion to her, John O'Connor's values would dictate that he would want to remain faithful even if incapacitated. Would Justice O'Connor have then, against her own judgment and values, been forced to comply with her husband's predementia critical interest values and take measures to end his relationship with the other resident?

Our policies consider such objections by providing that the resident can explicitly or implicitly revoke consent, even if incompetent, by providing a mechanism for a surrogate decision maker to trigger a process that can lead to basing future decisions on a broad best interest test that considers, among other matters, the resident's critical and experiential interests.

\section{A Domain-Specific and Risk-Sensitive Functional Competence Test}

1. The Test.-Stories like that of State v. Rayhons bring to light the need for a standardized, evidence-based approach to determining a nursing home resident's capacity to consent to sexual relations with her spouse or partner. No practical standardized functional capacity test has yet been proposed to determine capacity for demented residents. ${ }^{229} \mathrm{We}$ suggest a domain-specific, and risksensitive functional competence test for reconciling the multiple values at stake concerning nursing home residents' sexual relationships with others, particularly their spouses. This test emphasizes all adults' presumptive competence; rejects a rigid and impractical informed consent model sculpted for ideal, typical physician-patient relationships; and favors residents' critical, experiential, and best interests over undue concern with rare and unexpected episodes of exploitation by loved ones. Whether evaluating the demented resident's right to form new relationships in the facility or continue a relationship with a loved one, this model provides a framework within which to assess the resident's consent to sexual intimacy with a partner. Rayhons provides a real-world example of how each of the proposed test's steps could have been implemented; thus, potentially avoiding months of emotional pain and anguish and career-ending criminal charges.

2. Nursing Home Policies.-Before any effort is undertaken to implement a process of assessment and determination of consent to sexual activity, the nursing home should ensure it has policies that reflect an appropriate stance toward encouraging sexual self-determination and collaboration between the nursing home staff, the resident, and the resident's spouse or others.

226. Id.

227. $I d$.

228. $I d$.

229. White, supra note 12, at 151. 
Nursing home policies should include a policy statement explaining the facility's attitude toward the resident's right to privacy, right of selfdetermination, right of association, and right to sexual relationships when appropriate. It should invite the resident, spouse/partner, or, when a spouse/partner is not available, any close family member, to present a statement-which is written or, if by the resident directly when competent to consent or even when not competent by way of refusal, oral statement-regarding whether the resident shall be allowed to engage in (or shall be prohibited from engaging in) sexual activity with their spouse/partner, including if the residents are, or are in the future shown to be, legally incompetent. It should also state that, in the absence of any qualifying written or oral statement, it will be assumed the resident wants to have sexual activity with their spouse/partner if the spouse/partner confirms there has been implicit consent by the resident in the form of the resident's failure to resist any sexual encounter. The only way such explicit written, oral, or spousal statement of implicit consent shall be overridden is either if the resident, competent or not, expresses a desire not to have sexual activity or if an appointed surrogate or qualified employee appointed by the nursing home determines it is likely in the resident's best interests not to engage in sexual activity-best interests being judged by considering the resident's past relevant representations, other indications of the resident's critical and experiential interests, and the resident's physical and emotional well-being. If such a determination is made, the surrogate or appointed person shall ask the spouse or partner to certify that the resident has not objected to sexual activities, verbally or physically. If the spouse or partner refuses to so certify, sexual activities must be discontinued. If the surrogate or appointed person still believes it is not in the resident's best interests to engage in sexual activities with the spouse or partner, she should seek relief in court. If the matter is taken to court, the court should decide the matter under the broad best interests test set forth in the policies, and the burden of proof shall be upon the surrogate or appointed person who has brought the matter to court.

As mentioned earlier, an excellent example of a facility that comes close to embracing this recommended policy is the Hebrew Home in New York. ${ }^{230}$ A leader in the effort to recognize and embrace elder sexuality, the Hebrew Home staff encourages senior intimacy by facilitating a private environment for intimate encounters. ${ }^{231}$ The staff also engages, when appropriate, in conversations with the residents about their sexual encounters, and regularly and actively observes their emotional affect to identify indications of distress or anxiety as a possible effect of sexual relations. ${ }^{232}$ These policies help create an environment of resident selfdetermination while simultaneously offering safeguards against potential abuse situations.

230. Gruley, supra note 15 .

231. Id.

232. Id. 
In Rayhons, the absence of a policy affirming residents' rights to engage in sexual activity ${ }^{233}$ played a major role in the events leading to the husband's arrest for sexually assaulting his wife. Because the facility failed to promote an environment of open communication and encouragement of sexual expression, one of the facility's nurses told the resident's (wife) daughters "that on a number of occasions, [the resident] was wearing nothing but a robe after a visit from [her husband], and that staffers 'felt sickened by what he was doing to her." ${ }^{234}$ It is reasonable to speculate that a facility policy of open communication and encouragement of sexual expression might have resulted in reliance on a specific directive or at least an indication of implicit consent by the resident and a positive perception of the couple's sexual activity, and subsequently, a positive affirmation of its benefit when discussing the resident's needs and best interests with her daughters.

In Rayhons, upon the resident's admission to the Concord Care Center, the center not only failed to invite presentation of directives but also did not initiate any discussion about the couple's sexuality or the resident's wishes and expectations. Had it done so, as the resident's dementia progressed, the facility would have been prepared to discuss the couple's sexual encounters from a position of concern for protecting the resident's critical and experiential interests, rather than her lack of affirmative consent.

3. Ongoing Evaluation of the Resident's Expectations and Desires.-The evaluation of the resident's best interests is an ongoing process. Personnel of the nursing home shall notify the surrogate decision maker or qualified person appointed by the nursing home if they determine by ongoing and frequent respectful and sensitive communication or observation of the resident that he or she is being sexually abused. If the surrogate decision maker or qualified appointee is so notified or is concerned by her own observations, she shall make a determination whether it is likely the resident's best interests as broadly defined in these policies dictate no sexual activities, she shall respectfully request the spouse or partner affirm the resident has given implicit consent. If the spouse or partner refuses, sexual contact shall cease. If the spouse or partner provides written affirmation, but the surrogate decision maker or appointee still believes it is highly likely the resident's best interests dictate the resident not engage in sexual activities, she should seek court intervention, and the court shall use the same best interests test to make the ultimate determination. Throughout, the burden of proof shall be on the surrogate decision maker or appointee.

4. The Resident's Input Regarding Critical and Experiential Interests.-If we accept the premise that dementia is not an on/off switch that per se renders a person either competent or incompetent, but rather a variable state of lucidity and cognition, then we must also accept that a demented resident who is able to communicate in any manner presumptively has the ability to express her preferences and values. Dementia occurs on an unreliable continuum, and a resident's confusion today has no necessary bearing on her awareness tomorrow.

233. Gruley, supra note 154.

234. Id. 
Regardless, a resident's explicit refusal of sexual activity by oral statements or physical resistance shall control in all situations. Other than in this definitive situation, the resident's statements and actions indicating his or her critical and experiential interests shall be considered, but most weight should be given to such statements and actions in times during which the resident was or is at his or her mental best.

In Rayhons, there is no evidence that either the resident's caregivers or her daughters ever asked her if she liked having sex with her husband. ${ }^{235}$ In fact, after the resident's daughters moved her into a room with a roommate to "prevent 'potential sexual acts," her daughter's log reveals that the resident wept and accused her daughters of not liking her husband. ${ }^{236}$ These facts, if known to the nursing home, should have been given more weight.

a. Critical assessment.-If a married long-term care resident has completed an advance directive in which she explicitly declares her values and expectations related to continued sexual relations with her husband, despite her cognitive recognition at the time of a sexual encounter, she has made known her critical interests and they should be given considerable weight when assessing her current situation. If she has granted sexual power of attorney, her agent should weigh the resident's critical interests against any evidence that a continued sexual relationship with her husband or partner may be abusive or detrimental to her well-being. For example, a resident who has never exhibited a particular enjoyment of sex may nonetheless believe it is her "wifely duty" to have sex with her husband. This value, which superseded any personal enjoyment pre-dementia, may now extend to her critical interest value post-dementia. Despite a caregiver's, surrogate's, appointee's, or court's personal feelings about the resident's reasons, her values, regardless of whether rooted in arousal and gratification, should be recognized and considered to protect the resident's rights.

A confused resident who is not able to reason through a complex problem and is, at the time, unable to recall her last sexual encounter with her husband or partner may be still able to discuss her critical interests and personhood values. During periods of lucidity, she may be more specific and reaffirm any prior commitment to continue having sex with her husband or partner, despite her inability to fully recognize the implications of her actions at the time. Conversely, she may express dismay at having sex without full cognition of what she may be doing and with whom if she is incapacitated during the encounter. These observations and feelings must be acknowledged and honored to protect the resident from abuse.

Despite criticisms of the precedent autonomy and critical interests theory, advance directives provide valuable guidance when decision makers are grappling with the difficult issue of whether to "pull the plug" on further sexual intimacy with the resident's spouse or partner. Both critical interest and experiential theorists acknowledge that post-dementia, a "new person" conceivably may evolve, expressing a different set of values than those expressed in an advance

235. Id.

236. $I d$. 
directive. The question decision makers must consider is whether to adhere to the resident's pre-dementia values despite evidence that they are no longer those of the "new" person, or rely on evidence of experiential interests that may be in conflict with her critical interests.

In Rayhons, there is every indication that the resident was in love with her husband when she was placed in Concord Care Center. ${ }^{237}$ They had been married seven years and enjoyed each other's company, spending every available minute together. ${ }^{238}$ By all accounts, they enjoyed a vigorous sex life. ${ }^{239}$ During the early weeks of her residence at Concord, the staff noted that the resident was "pleasant, alert and occasionally forgetful." 240 She engaged in conversation with the other residents and "enjoyed bingo, music and other activities." 241 Clearly, the resident was still capable of communicating her critical interests, had anyone but asked.

b. Experiential assessment.-Dementia does not prevent a person from expressing desires and other emotions, nor does it prevent them from experiencing pleasure. Although verbal capacity may be affected, persons with dementia express themselves through facial expression, body language, and other external cues that long-term care administrators and caregivers can observe and document to indicate functional consent. ${ }^{242}$ Using these verbal and non-verbal cues, the attentive caregiver can identify the resident's experiential interests, such as whether the resident enjoys ice cream at lunch, likes the bluegrass band that plays on Friday evenings, or prefers to sit outside or in the common room. Likewise, the caregiver can ascertain if the resident enjoyed her husband's visit, if she looks forward to seeing him again, if sex was painful or difficult, and if the resident displays any distress when talking about her husband or partner.

A careful observation of the demented resident's mental and emotional affect following a sexual encounter with her husband or partner can indicate whether the resident perceived the encounter as pleasurable or stressful and abusive. For example, the resident (wife) in Rayhons, according to Concord staff, was "always pleased to see [her husband]." ${ }^{243}$ The resident reportedly would hug her husband, hold his hand, and smile while they talked. ${ }^{244}$ The resident reportedly enjoyed sex with her husband, and occasionally even asked for $\mathrm{it}^{245}$ by saying, "Shall we play a little bit?"246 The resident's daughter told a state investigator that the resident

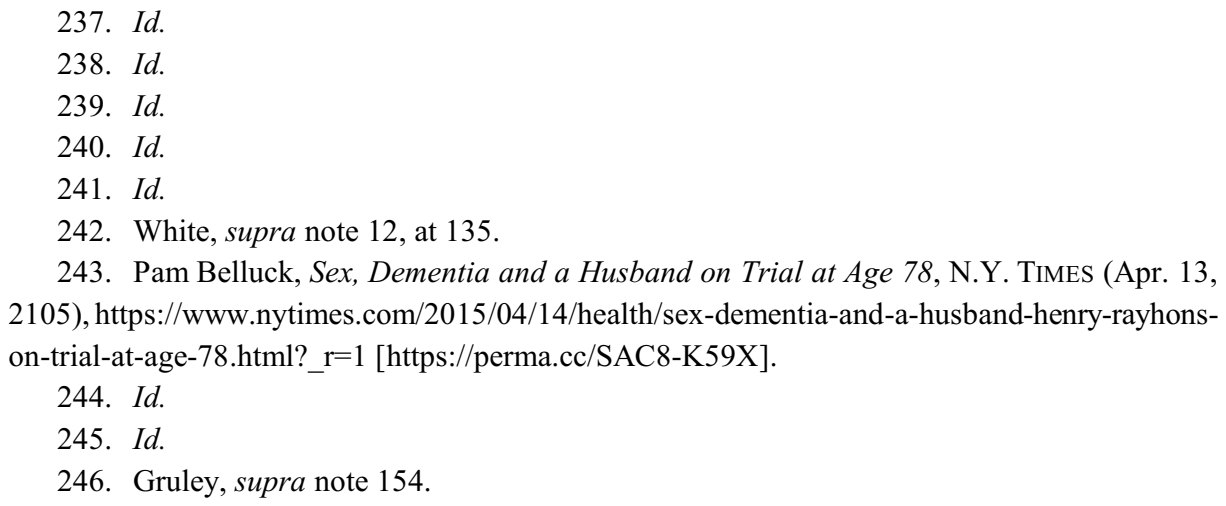

243. Pam Belluck, Sex, Dementia and a Husband on Trial at Age 78, N.Y. Times (Apr. 13, 2105), https://www.nytimes.com/2015/04/14/health/sex-dementia-and-a-husband-henry-rayhonson-trial-at-age-78.html?_r=1 [https://perma.cc/SAC8-K59X].

244. Id.

245. Id.

246. Gruley, supra note 154. 
once pointed at her crotch and said, "Henry [her husband] likes this a lot."247 When her daughter had her moved into a room with a roommate, the resident wept and accused her daughter of not liking [her husband]. ${ }^{248}$ An observant and objective caregiver might have seen the resident's responses to her husband as indicative of her experiential interests in maintaining a sexual relationship with him.

Alternatively, indications that the resident is distressed about her husband's or partner's visit or sexual advances are a possible indicator of abuse or withdrawal of consent. As the "new person" emerges throughout the progression of dementia, the resident may no longer feel attracted to her husband or lover, and may feel violated by their advances. A conference with the resident's husband or partner to discuss her reactions may be sufficient to dissuade any future unwanted advances. If not, the surrogate or appointee can trigger the formal processes outlined in the policies.

\section{CONCLUSION}

Angela Nelson was a juror in State v. Rayhons. ${ }^{249}$ In her account of the experience, she said, "I believe the criminal in this is anyone who labeled [the resident] 'defective,' who tried to remove [the resident's] basic human rights without asking her or a court to decide." ${ }^{.250}$ A new approach to determining a demented resident's capacity to consent is needed. The historical approach, which is still widely utilized, risks compromising the demented resident's rights. Although a nursing home has an obligation to protect residents from harm, it has at least an equal duty to maximize benefits to the resident and honor resident's rights.

Some people will adhere to the critical interest theory, that our values formed pre-dementia should control decisions made on our behalf post-dementia. ${ }^{251}$ Others will identify with the experiential interest theorists who assert that the interests of the "new person" now occupying the demented individual's body should take priority over any precedent autonomy of the non-demented former person. ${ }^{252}$ Regardless of which theory one believes is more accurate, it is well established that dementia occurs on a continuum of evolving and variable symptoms. ${ }^{253}$ It is further established that a person with dementia may be incompetent in one area and fully capable of reasoning and making decisions in

247. $I d$.

248. Id.

249. Angela Nelson, The Rayhons Trial: A Jurors Perspective, KIOW Mix 107.3 (Dec. 31, 2015), http://kiow.com/2015/12/31/rayhons-trial-a-jurors-perspective/ [https://perma.cc/N6MK$\mathrm{X} 4 \mathrm{SK}]$.

250. Id. (emphasis added).

251. See supra Part VI.A.

252. See id.

253. See 2015 Alzheimer's Disease Facts And Figures, supra note 5, at 11. 
another. ${ }^{254}$ Therefore, a complete adherence to one theory or the other can ultimately result only in violation of the resident's rights.

This Article proposes that long-term care facilities need to carefully examine their ideals, attitudes, and beliefs about the sexuality of demented residents, while considering the controlling law in their jurisdiction. Based on this analysis, facilities should be made to adopt or voluntarily adopt the policies suggested in this Article. Furthermore, nursing homes should, through training and reinforcement, ensure every staff member embraces and supports the policies. No policy or system of assessments will succeed if all parties are not fully informed of their rights and choices and the jurisdictional law governing those choices. This first step, then, will ensure the long-term care facility staff are trained to recognize potentially problematic situations and to respond to them appropriately.

Upon admission to the facility, while she retains the capacity to consider her values, options, and desires, the new resident should be engaged in a frank and candid discussion about her sexual preferences and expectations. If appropriate, she should memorialize them in an advance directive. She should also consider granting sexual power of attorney to a trusted third party who can objectively assess the benefit or harm of continued sexual relations with her husband or partner, and who will make, when appropriate, decisions in her bests interest that reflect the resident's wishes as indicated in her advance directives and as reflected by her critical and experiential interests.

If a married resident's critical interests support a continued sexual relationship with her husband or partner, and if there are no external cues that the resident does not want any sexual encounter with her husband or partner, a condition of consent must be presumed. If, however, the external cues indicate distress, depression, or sadness after a sexual encounter, the surrogate or appointee identified in the suggested policies must determine whether to seek affirmation of implicit consent by the spouse or partner. Further, the surrogate should seek to obtain relief from the court if, despite a spousal or partner affirmation, he determines that it is not in the resident's best interests to continue sexual activities. All decision makers should determine the resident's best interests by considering the resident's past relevant representations, other indications of the resident's vital and experiential interests, and the resident's physical and emotional well-being.

The policies proposed here provide family and nursing homes and their staff the tools to protect the demented resident's right to have sex with her husband or partner if she manifests her desire through explicit consent, advance directives, or external cues of pleasure and enjoyment. Simultaneously, it provides appropriate measures to protect her from being forced to engage in an unwanted intimate relationship and risking its associated physical, mental, and health risks. Demented residents of long-term care facilities should have the right to say "yes" to sex with their husbands or partners, as do those who live within the confines of their own homes.

254. Tenenbaum, supra note 2 , at 711 . 